ORIGINAL ARTICLE

\title{
Unintentional and undetermined firearm related deaths: a preventable death analysis for three safety devices
}

\author{
J S Vernick, M O'Brien, L M Hepburn, S B Johnson, D W Webster, S W Hargarten
}

Injury Prevention 2003;9:307-311

See end of article for authors' affiliations a.................

Correspondence to: Jon S Vernick, Johns Hopkins Bloomberg School of Public Health, Center for Gun Policy and Research, $624 \mathrm{~N}$ Broadway, Baltimore, MD 21205,

USA; JVernick@jhsph.edu

\begin{abstract}
Objective: To determine the proportion of unintentional and undetermined firearm related deaths preventable by three safety devices: personalization devices, loaded chamber indicators (LCls), and magazine safeties. A personalized gun will operate only for an authorized user, a $\mathrm{LCl}$ indicates when the gun contains ammunition, and a magazine safety prevents the gun from firing when the ammunition magazine is removed.

Design: Information about all unintentional and undetermined firearm deaths from 1991-98 was obtained from the Office of the Chief Medical Examiner for Maryland, and from the Wisconsin Firearm Injury Reporting System for Milwaukee. Data regarding the victim, shooter, weapon, and circumstances were abstracted. Coding rules to classify each death as preventable, possibly preventable, or not preventable by each of the three safety devices were also applied.

Results: There were a total of 117 firearm related deaths in our sample, 95 (81\%) involving handguns. Forty three deaths (37\%) were classified as preventable by a personalized gun, $23(20 \%)$ by a $\mathrm{LCl}$, and five $(4 \%)$ by a magazine safety. Overall, 52 deaths (44\%) were preventable by at least one safety device. Deaths involving children 0-17 (relative risk (RR) 3.3, 95\% confidence interval (CI) 2.1 to 5.1 ) and handguns (RR 8.1, 95\% Cl 1.2 to 53.5) were more likely to be preventable. Projecting the findings to the entire United States, an estimated 442 deaths might have been prevented in 2000 had all guns been equipped with these safety devices.

Conclusion: Incorporating safety devices into firearms is an important injury intervention, with the potential to save hundreds of lives each year.
\end{abstract}

R ather than relying exclusively on changing the behavior of the users of dangerous products, injury prevention efforts have also focused on changing the design of the product itself to make it safer. ${ }^{1}$ Of consumer products in the United States, firearms are among the most deadly. From 1990 to 1999 , there were more than 12000 unintentional firearm related deaths in the United States, with an additional 4000 deaths in the "undetermined" category. ${ }^{2}$ Yet firearms can be designed with built-in safety features that may prevent at least some of these deaths. ${ }^{3}$

Injury prevention efforts to improve the safe design and manufacture of guns have concentrated primarily on three safety technologies: (1) personalization devices, (2) loaded chamber indicators (LCIs), and (3) magazine safeties. A personalized gun is a firearm that will fire only for an authorized user. This can be accomplished through a variety of user-recognition technologies-for example, fingerprint readers - that can be built into the design of the gun. Unless the firearm recognizes its authorized user, it is unable to fire. ${ }^{45}$

A LCI is a device designed to indicate that the gun's firing chamber contains ammunition. ${ }^{6}$ LCIs are intended to prevent firearm related deaths where the gun's operator did not know the gun was loaded. At present, loaded chamber indicators are included on about $10 \%-20 \%$ of new pistol models. ${ }^{67}$ However, existing loaded chamber indicators generally consist of a small raised lever or button on the gun, with no additional markings to convey its meaning. Patents exist, however, for LCIs that would be far easier for operators to understand. ${ }^{6}$ A magazine safety (sometimes also called a magazine disconnect safety) blocks a semiautomatic pistol from firing when its ammunition magazine is removed, even if there is still a round in the chamber. ${ }^{8}$

Although all three of these safety devices have been widely discussed and promoted in both the public health and popular literature, there have been few attempts to quantify their potential benefits. The United States General Accounting Office estimated that $23 \%$ of a sample of unintentional deaths were preventable by a loaded chamber indicator and $8 \%$ by a childproofing device. ${ }^{9}$ The childproofing device considered in the General Accounting Office study was intended to prevent discharge by young children only (age $<6$ ), and therefore was not a personalized gun. Similarly, Ismach and colleagues concluded that in $14 \%$ of the incidents in their sample of mostly non-fatal firearm injuries the shooter was unaware that the gun was loaded; in 5\% the handgun's ammunition magazine had been removed just before the shooting. ${ }^{10}$ From a North Carolina sample, Cherry and colleagues determined that the shooter believed the gun was unloaded in 39 of $187(21 \%)$ unintentional firearm related deaths. ${ }^{11}$

Using data from Maryland and Milwaukee, Wisconsin, this study examines the proportion of certain firearm related deaths that might be preventable by each of the three major safety devices. By including personalization technology, our analysis allows for a comparison of the relative benefits of the different devices.

\section{METHODS}

\section{Data sources}

Information about firearm related deaths was obtained from two primary sources: the Maryland Office of the Chief Medical Examiner, and the Wisconsin Firearm Injury Reporting System (FIRS). We reviewed the case files for all

Abbreviations: $\mathrm{Cl}$, confidence interval; FIRS, Firearm Injury Reporting System; LCl, loaded chamber indicator; RR, relative risk 
unintentional and undetermined firearm related deaths in Maryland and Milwaukee County for 1991-98. These files include information obtained from medical examiner investigations, police files, and crime laboratory reports. For each firearm related death, we abstracted a variety of information about the victim, shooter, weapon, and circumstances of the death. Deaths associated with non-powder firearms (for example, airguns and bb guns) were excluded. The combined dataset represents a convenience sample based on the ease of obtaining the data, their relative quality and completeness, and the value of increasing the overall sample size.

Medical examiners sometimes code certain, seemingly unintentional, deaths as homicides (rather than "accidents") where the gun's trigger is intentionally pulled, even if the shooter did not intend to cause the death of the victim. ${ }^{12}{ }^{13}$ This may be based on a technical, rather than intent based, definition of a homicide as one where the actions of one person result in the death of another. Therefore, using the Wisconsin surveillance system (FIRS), we separately identified those "homicides" in Milwaukee County where (1) the circumstances of the death indicated an accidental firingsuch as playing with or cleaning a firearm and (2) the Federal Bureau of Investigation's Supplemental Homicide Reports data similarly coded the death as a "negligent manslaughter". ${ }^{14}$ In the absence of a comparable surveillance system, it would have been much more difficult to conduct a similar analysis of Maryland homicides.

Preliminary analyses of these negligent homicides in Milwaukee indicated that, as expected, their circumstances were very similar to both the accidental and undetermined deaths in Milwaukee County. Similarly, unintentional and undetermined deaths, as well as the combined data for Maryland and Milwaukee shared comparable age, sex, and type of gun characteristics. Our assessment of the circumstances of these deaths also suggested that the events surrounding unintentional and undetermined deaths were very similar. For these reasons, and to increase the precision of our point estimates, subsequent analyses combine the data from Maryland and Milwaukee.

Suicides and non-negligent homicides are not included in this analysis. Medical examiner and police records rarely contained detailed information about the circumstances of the death (for the suicides), or whether the shooter was the owner or an authorized user of the gun (for homicides). In addition, the factors associated with preventability may have been different for these intentional deaths.

\section{Definition of a "preventable" death}

Our primary goal was to estimate the proportion of the firearm related deaths in our sample that might have been prevented by one or more of the three safety devices. For each case, two reviewers (JV, MO) applied a set of rules to code the death as (1) "preventable", (2) "possibly preventable", or (3) "not preventable". The very small number of cases where reviewers disagreed were resolved by a third reviewer (SJ) or by consensus.

For LCIs, a death was coded as preventable only if the case file indicated clear evidence that the shooter did not realize the gun was loaded at the time of the shooting. Usually this was based on unambiguous statements of witnesses interviewed by the police. In addition, the shooter must be old enough to understand the message to be conveyed by a LCI; to be conservative in this regard, we established a minimum age of 10 . We coded the death as possibly preventable if there was only some evidence that the shooter thought the gun was unloaded. We assume (based on patent information) that such devices could be applied to any firearm, and can be designed so that even an untrained user would understand that the gun was loaded.
For personalized guns, a death was considered preventable if there was clear evidence in the case file that the shooter was not the owner or authorized user of the gun. For example, personalized guns can prevent deaths where the shooter is below the legal age for gun ownership-by definition an unauthorized user. We recognize that this assumes that adult owners of personalized handguns will not provide them to children, an assumption that might not always be correct. We coded deaths as "possibly" preventable by personalized guns when the case file indicated some evidence that the shooter was not an authorized user.

For magazine safeties, our preventability criteria required clear evidence that the shooter removed the ammunition magazine from a semiautomatic pistol immediately before the shooting. Where there was less clear evidence, the deaths were coded as possibly preventable.

For all of the devices, we conservatively coded the death as "not preventable by safety devices" if it did not meet any of the above criteria. It is important to recognize that characterizing a death as "preventable" does not mean that it would certainly have been prevented by the relevant safety device-only that, applying our rules, we determine that the death could have been prevented.

\section{Analyses}

Applying our criteria, for each of the safety devices we calculate the proportion of the deaths in our sample that fit the three categories of preventability. We also conducted bivariate analyses of deaths coded as preventable, compared with those coded as not preventable, to examine factors associated with differences between these two groups. To test the statistical significance of these bivariate analyses, $\chi^{2}$ tests of independence, calculation of relative risks, and confidence intervals were used. Finally, extrapolating from our data, we calculate the number of lives that might be saved in the United States by these devices.

\section{RESULTS}

There were a total of 117 unintentional, undetermined, and negligent homicide deaths in our data set for 1991 to 1998, 66 in Maryland and 51 in Milwaukee (see table 1). Males (91\%) and persons aged 0-20 (53\%) represent the majority of the decedents. Handguns were involved in $81 \%$ of the deaths, with roughly equal proportions of pistols and revolvers. Among the circumstances of the incident, "playing with or showing the gun to others" (51\%), and "handling or transporting the gun" (21\%) represented nearly three quarters of all deaths.

Among all deaths, 43 (37\%) met our criteria for being "preventable" by a personalized gun, $23(20 \%)$ by a loaded chamber indicator, and five $(4 \%)$ by a magazine safety. A smaller proportion of deaths for each device were classified as "possibly preventable" (see table 2 ).

Overall, 52 of the deaths $(44 \%, 95 \%$ confidence interval (CI) $35 \%$ to $53 \%$ ) fit our criteria as preventable by at least one of the devices. Some were preventable by more than one device. Importantly, there was no statistically significant difference in overall preventability by site $\left(\chi^{2}=0.74\right.$, $\mathrm{p}=0.39$ ), reinforcing our decision to combine the Maryland and Milwaukee data for analysis. Also, no type of death was significantly more likely to be preventable than any other, whether unintentional, undetermined, or negligent homicide $\left(\chi^{2}=0.14, p=0.93\right)$. Again, this suggests that the relevant characteristics of these deaths are similar enough to justify combining the data for our purposes.

In the bivariate analyses, we compared preventable with non-preventable deaths, excluding those that were only "possibly" preventable. In these analyses, several characteristics of the deaths were associated with higher proportions 
Table 1 Selected characteristics of unintentional, undetermined, and negligent homicide firearm related deaths in Maryland and Milwaukee, 1991-98

\begin{tabular}{|c|c|}
\hline Variable* & No $(\%)$ \\
\hline \multicolumn{2}{|l|}{ Age (years) } \\
\hline $0-17$ & $46(39)$ \\
\hline $18-20$ & 16 (14) \\
\hline $21-40$ & 37 (32) \\
\hline $41+$ & $18(15)$ \\
\hline \multicolumn{2}{|l|}{ Sex } \\
\hline Male & $107(91)$ \\
\hline Female & $10(9)$ \\
\hline \multicolumn{2}{|l|}{ Race } \\
\hline White & $60(51)$ \\
\hline Black & $54(46)$ \\
\hline Other & $3(3)$ \\
\hline \multicolumn{2}{|l|}{ Site/type of death } \\
\hline \multicolumn{2}{|l|}{ Maryland $(n=66)$} \\
\hline Unintentional & $20(30)$ \\
\hline Undetermined & $46(70)$ \\
\hline \multicolumn{2}{|l|}{ Milwaukee $(n=51)$} \\
\hline Unintentional & $13(25)$ \\
\hline Undetermined & $12(24)$ \\
\hline Negligent homicide & $26(51)$ \\
\hline \multicolumn{2}{|l|}{ Circumstance } \\
\hline Cleaning & $3(3)$ \\
\hline $\begin{array}{l}\text { Handling/transporting/loading/ } \\
\text { unloading }\end{array}$ & $25(21)$ \\
\hline Hunting & $6(5)$ \\
\hline Miscellaneous/other & $5(4)$ \\
\hline Playing with/showing gun to others & $60(51)$ \\
\hline $\begin{array}{l}\text { Thought safety was on/problem with } \\
\text { safety }\end{array}$ & $4(3)$ \\
\hline Unknown & $14(12)$ \\
\hline \multicolumn{2}{|l|}{ Type of gun } \\
\hline \multicolumn{2}{|l|}{ Handgun $(n=95)$} \\
\hline Pistol & $42(36)$ \\
\hline Revolver & $45(38)$ \\
\hline Unknown/other & $8(7)$ \\
\hline \multicolumn{2}{|l|}{ Long gun $(n=19)$} \\
\hline Rifle & $9(8)$ \\
\hline Shotgun & $10(9)$ \\
\hline \multicolumn{2}{|l|}{ Missing $(n=3)$} \\
\hline $\begin{array}{l}\text { *Age, sex, and race data refer to the de } \\
\text { not the decedent is also the shooter. Circ } \\
\text { of gun refer to characteristics of the ever }\end{array}$ & $\begin{array}{l}\text { dent, whether or } \\
\text { mstance and type }\end{array}$ \\
\hline
\end{tabular}

of preventability (see table 3 ). Incidents where the decedent was aged $0-17$ were three times as likely to be preventable (relative risk (RR) 3.3, 95\% CI 2.1 to 5.1) as those involving all older persons. Deaths involving handguns were eight times as likely to be preventable (RR $8.1,95 \%$ CI 1.2 to 53.5 ) as those involving long guns. Among the circumstances of the incident, deaths that involved "playing with or showing the gun to others" were most likely to be preventable (RR 3.2, 95\% CI 1.9 to 65.3 ).

Based on our estimates of the proportion of deaths preventable by any safety device $(44 \%, 95 \%$ CI $35 \%$ to $53 \%$ ), we can calculate the number of lives that might be saved if all firearms had all three devices. In 2000, there were 776 unintentional firearm deaths in the United States. Applying our results yields an estimate of 341 unintentional deaths (95\% CI 272 to 411 ) that might have been prevented. There were also 230 firearm deaths of undetermined intent in 2000 , producing an estimate of 101 preventable deaths $(95 \%$ CI 81 to 122 ) in this category. Combining these data, 442 lives might have been saved in 2000 if all firearms had all three safety devices (95\% CI 353 to 533).

\section{DISCUSSION}

Overall, more than $40 \%$ of the firearm related deaths in our sample were preventable by at least one of the three safety devices. Providing all three of these devices in all firearms
Table 2 Number (\%) of preventable firearm deaths by various safety devices in Maryland and Milwaukee, 1991-98

\begin{tabular}{|c|c|c|c|c|}
\hline & $\begin{array}{l}\text { Personalized } \\
\text { gun }\end{array}$ & LCI & $\begin{array}{l}\text { Magazine } \\
\text { safety }\end{array}$ & $\begin{array}{l}\text { Any of three } \\
\text { safety devices' }\end{array}$ \\
\hline \multirow{4}{*}{$\begin{array}{l}\text { Preventable } \\
\text { Possibly } \\
\text { preventable† } \\
\text { Not } \\
\text { preventable } \\
\text { by safety } \\
\text { devices } \\
\text { Total }\end{array}$} & $43(37)$ & $23(20)$ & $5(4)$ & $52(44)$ \\
\hline & $13(11)$ & $15(13)$ & $3(3)$ & $19(16)$ \\
\hline & $61(52)$ & $79(68)$ & $109(93)$ & $46(39)$ \\
\hline & $117(100)$ & $117(100)$ & $117(100)$ & $117(100)$ \\
\hline
\end{tabular}

*Because the same death may be preventable by more than one device, figures in this column are not the sum of the other three columns. tFor personalized guns, this category includes deaths where the shooter was not in immediate control of the firearm when it discharged (for example, a firearm that discharged when dropped from a tree stand while hunting). For loaded chamber indicators ( $(\mathrm{Cls})$, this category includes so-called Russian roulette shootings (a $\mathrm{LCl}$ might eliminate the element of chance from this activity).

\begin{tabular}{|c|c|c|}
\hline Variable & $\begin{array}{l}\text { Percent } \\
\text { preventable }\end{array}$ & $\begin{array}{l}p \text { Value } \\
\text { for } \chi^{2 *}\end{array}$ \\
\hline Age (years) & & $<0.001$ \\
\hline $0-17$ & 88 & \\
\hline $18-20$ & 62 & \\
\hline $21-40$ & 19 & \\
\hline $41+$ & 13 & \\
\hline Type of gun & & $<0.001$ \\
\hline Handgun & 62 & \\
\hline Long gun & 8 & \\
\hline Circumstance & & $<0.001$ \\
\hline Hunting & 33 & \\
\hline Handling/transporting/loading & 27 & \\
\hline $\begin{array}{l}\text { Playing with/showing gun } \\
\text { to others }\end{array}$ & 80 & \\
\hline $\begin{array}{l}\text { Thought safety was on/problem } \\
\text { with safety }\end{array}$ & 50 & \\
\hline Unknown & 23 & \\
\hline \multicolumn{3}{|c|}{$\begin{array}{l}\text { *For each of the variables (age, type of gun, circumstance), } \\
\text { the } \chi^{2} \text { tests the null hypothesis that the proportion of } \\
\text { preventable firearm related deaths across the appropriate } \\
\text { subcategories (that is, the different age, type of gun, and } \\
\text { circumstance groupings) is the same. }\end{array}$} \\
\hline
\end{tabular}

could save more than 400 lives each year. Other research suggests that there would also be significant cost savings associated with preventing firearm related deaths, both for the victims' families and for the community as a whole. ${ }^{15} 16$ Of course, any assessment of the desirability of the devices should weigh the benefits in lives saved (and injuries averted) against the costs to consumers of providing or requiring the devices.

Our conclusion that $20 \%$ of the deaths were preventable by a LCI is convincingly close to prior research, falling between the General Accounting Office's 23\% figure, and Ismach et al's 14\%. No prior research has examined the proportion of deaths preventable by a personalized gun. Yet our results suggest that personalized guns may be among the most beneficial firearm safety design changes for the future.

However, personalized guns are not uniformly supported by gun control advocates. In fact, some have argued that increased availability of these guns may even be counterproductive. ${ }^{17}$ Our research can help clarify the risk-benefit 
equation for these guns by providing better information about how many lives might be directly saved by personalized guns. For loaded chamber indicators and magazine safeties, these concerns are minimized because potential gun buyers already have the option to purchase guns with these features.

Just $4 \%$ of the deaths in our sample were preventable by a magazine safety. The action of removing the ammunition magazine from a pistol prior to the shooting is apparently less common than other circumstances surrounding firearm related deaths, or at least is less frequently noted in medical examiner and police reports. However, the passive or automatic nature of magazine safeties, coupled with their relatively low price and mechanical simplicity, suggests that these devices remain a useful injury intervention.

Although safer handling or storage of firearms might also have prevented some of the deaths in our sample, this was not the focus of our research. In addition, there is some evidence that it may be quite difficult to alter the firearm handling, ownership, or storage practices of children ${ }^{18} 19$ and adults. ${ }^{20-23}$

For the present study we did not examine the safety devices' effects on suicides and non-negligent homicides. Personalized guns, in particular, might prevent youth suicides, and even some homicides where the gun was recently stolen from its owner. Future research, based on newly developed surveillance systems, might therefore yield greater estimates of the number of lives saved by these devices when all deaths are included.

\section{Limitations}

Our study has several limitations. There is inherent uncertainty in any determination of whether some safety device might have prevented any given death. We have tried to minimize some of this uncertainty by establishing reasonably specific rules and by using multiple coders. With data from Maryland and Milwaukee, the generalizability of our findings to other areas or to the United States as a whole is uncertain. However, the comparability of our findings regarding preventability among the two regions, and with other research, suggests that regional variation in preventability within the United States may not be especially great. The age distribution of our sample is somewhat younger than the nation as a whole, though the gender distribution is similar to national data.

As described, we did not include negligent homicides in Maryland. However, the purpose of our analysis was not to determine the raw number of preventable deaths, but the proportion of deaths that might be prevented by the various safety devices. Only if the proportion of negligent homicides in Maryland that were preventable was very different from the rest of the deaths in our sample would their absence affect our results. The similarity in preventability of Milwaukee's negligent homicides with the rest of the deaths suggests that this is probably not the case.

For several reasons, our estimate of the number of lives that might be saved by the three safety devices may be conservative. First, the reported number of unintentional deaths in the United States is likely to be an underestimate since many of these deaths, as in our Milwaukee data, are coded as negligent homicides. Inclusion of these negligent homicides substantially increased the number of Milwaukee cases in our sample. Also, in our calculations of lives potentially saved, we use only those deaths we classified as preventable, not those classified as possibly preventable.

On the other hand, we understand the uncertainties inherent in this or any calculation of possible lives saved under various assumptions. For example, this calculation assumes that the proportion of deaths preventable in our sample would be the same for the United States as a whole.
In addition, our lives saved calculations assume that all firearms would have the safety devices. Of course, even if new firearms were required to contain the devices, many older guns without the devices would remain in circulation. Therefore, it might be some years before the maximum benefit of the technologies would be felt. We also assume that LCIs can be designed, as a new California law requires, to be understood even by untrained users. ${ }^{24}$

Some might even argue that the inclusion of new safety devices into firearms could result in the loss of lives, for example if the firearm did not function as intended during a defensive gun use, or if the increased cost forced some to forgo the purchase of a gun. Designers of personalized guns attempt to minimize or eliminate any interference with the normal operation of the firearm. LCIs and magazine safeties should result in little change to the operation or cost of a gun. The increased cost of personalized guns, and the impact this might have on purchasing decisions, is not known. In addition, despite the arguments of some researchers, ${ }^{25}$ the best available evidence suggests that there are relatively few defensive uses of guns compared with gun related deaths and crimes. ${ }^{26} 27$

\section{CONCLUSION}

Despite the potentially lifesaving benefits of firearm safety technologies, most firearm manufacturers have not provided these devices voluntarily. ${ }^{7}$ In the United States, the public would support legislation requiring these devices. In one national poll, legislation requiring all new handguns to contain a LCI (73\% in favor) or personalization technology ( $71 \%$ in favor) were each supported by a large majority of the respondents. ${ }^{28}$

Certainly, incorporating safety devices into firearms is not the only appropriate strategy for responding to the many different causes of firearm violence. However, examples of successful design changes for other products (such as motor vehicles and prescription drug containers), ${ }^{29}{ }^{30}$ coupled with the results of our study, suggest that product modification should remain an important intervention for firearms as well.

\section{ACKNOWLEDGEMENTS}

The authors gratefully acknowledge funding for this research from the Funders' Collaborative for Gun Violence Prevention. We also thank Allegra Kim for her assistance, and the Offices of the Medical Examiners for Milwaukee and Maryland for collecting and making available the data for this study.

\section{Key points}

- Changing the design of products to make them safer is a proven injury prevention strategy, but for firearms this strategy has not yet been widely adopted.

- For firearms, loaded chamber indicators and magazine safeties are designed to prevent some deaths where the shooter did not know the gun was loaded; personalization devices prevent the gun from being fired by an unauthorized user.

- In this study of the lifesaving potential of these three firearm safety devices, $44 \%$ of the deaths in the sample were preventable by at least one of the devices.

- Design changes to firearms have the potential to save hundreds of lives each year in the United States. 


\section{Authors' affiliations}

J S Vernick, S B Johnson, D W Webster, Johns Hopkins School of Public Health, Center for Gun Policy and Research, Baltimore, Maryland M O'Brien, L M Hepburn, Harvard School of Public Health, Injury Control Research Center, Cambridge, Massachusetts

S W Hargarten, Medical College of Wisconsin, Firearm Injury Center, Milwaukee, Wisconsin

\section{REFERENCES}

1 National Committee for Injury Prevention and Control. Injury prevention: meeting the challenge. New York, NY: Oxford University Press, 1989:7-8.

2 Centers for Disease Control and Prevention. Web-based Injury Statistics Query and Reporting System (WISQARS). Available at http://www.cdc.gov/ ncipc/osp/data.htm (accessed on 10 April 2003).

3 Freed LH, Vernick JS, Hargarten SW. Prevention of firearm-related injuries among youth: a product oriented approach. Pediatr Clin North Am 1998;45:427-38

4 Teret SP, Culross PL. Product-oriented approaches to reducing youth gun violence. Future Child 2002;12:119-31.

5 Teret SP, Lewin NL. Policy and technology for safer guns: an update. Ann Emerg Med 2003;41:32-4.

6 Vernick JS, Meisel ZF, Teret SP, et al. "I didn't know the gun was loaded": an examination of two safety devices that can reduce the risk of unintentional firearm injuries. J Public Health Policy 1999;20:427-40.

7 Milne JS, Hargarten SW, Kellermann AL, et al. Effect of current federal regulations on handgun safety features. Ann Emerg Med 2003:41:1-9.

8 Karlson TA, Hargarten SA. Reducing firearm injury and death: a public health sourcebook on guns. New Brunswick, NJ: Rutgers University Press, 1997:71-2.

9 United States General Accounting Office. Accidental shootings: many deaths and injuries caused by firearms could be prevented. Washington, DC: United States General Accounting Office, 1991:1-47.

10 Ismach RB, Reza A, Ary R, et al. Unintended shootings in a large metropolitan area: an incident based analysis. Ann Emerg Med 2003:41:10-17.

11 Cherry D, Runyan C, Butts J. A population based study of unintentional firearm fatalities. Inj Prev 2001;7:62-5.

12 Barber CW, Ozonoff VV, Schuster M, et al. Massachusetts weapon-related injury surveillance system. Am J Prev Med 1998;15(suppl 3):57-66.
13 Frattaroli S Webster DW Teret SP. Unintentional gun injuries, firearm design, and prevention: what we know, what we need to know, and what can be done. J Urban Health 2002;79:49-59.

14 Barber C, Hemenway D, Hochstadt J, et al. Underestimates of unintentional firearm fatalities: comparing Supplementary Homicide Report data with the National Vital Statistics System. Inj Prev 2002;8:252-6.

15 Cook PJ, Ludwig J. Gun violence: the real costs. New York, NY: Oxford University Press, 2000:97-115.

16 Cook PJ, Lawrence BA, Ludwig J, et al. The medical costs of gunshot injuries in the United States. JAMA 1999;282:447-54

17 Sugarmann J. Loaded logic: making guns smart won't stop killings like the one in Michigan. Washington Post 2002, March 5: B2.

18 Hardy MS, Armstrong FD, Martin BL, et al. A firearm safety program for children: they just can't say no. J Dev Behav Pediatr 1996;17:216-21.

19 Jackman GA, Farah MM, Kellermann AL, et al. Seeing is believing: what do boys do when they find a real gun? Pediatrics 2001; 107:1247-50.

20 Brent DA, Baugher M, Birmaher B, et al. Compliance with recommendations to remove firearms in families participating in a clinical trial for adolescent depression. J Am Acad Child Adolesc Psychiatry 2000;39:1220-6.

21 Hemenway D, Skolnick SJ, Azrael DR. Firearm training and storage. JAMA 1995;273:46-50

22 Connor SM, Wesolowski KL. "They're too smart for that": predicting what children would do in the presence of guns. Pediatrics 2003:111:e109-14.

23 Grossman DC, Cummings P, Koepsell TD, et al. Firearm safety counseling in primary care pediatrics: a randomized, controlled trial. Pediatrics 2001;106:22-6.

24 California Senate. Bill No 489, September 2003.

25 Kleck G, Gertz M. Armed resistance to crime: the prevalence and nature of self-defense with a gun. Journal of Criminal Law and Criminology 1995;86:150-87.

26 McDowall D, Wiersema $B$. The incidence of defensive firearm use by US crime victims, 1987-1990. Am J Public Health 1994;84:1982-4.

27 Hemenway D. Survey research and self-defense gun use: an explanation of extreme overestimates. Journal of Criminal Law and Criminology 1997;87:1430-45

28 Teret SP, Webster DW, Vernick JS, et al. Public support for innovative gun policies: the results of two national surveys. N Engl J Med 1998;339:813-8.

29 Rogers GB. The safety effects of child-resistant packaging for oral prescription drugs: two decades of experience. JAMA 1996;275:1661-5.

30 National Highway Traffic Safety Administration. Effectiveness of occupant protection systems and their use, fourth report to Congress. Washington, DC: US Department of Transportation, 1999:i.

\section{$\mathrm{ECHO}$}

\section{Lighter balls for younger children}

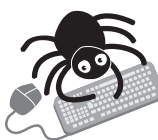

Please visit the Injury

Prevention website [www. injuryprevention.com] for a link to the full text of this article. he incidence of hand and wrist injuries from balls used by children in sporting activities may be reduced by increasing awareness of parents and coaches, using lighter balls, and introducing weight categories for players.

The case notes of all children aged 6-13 years attending the accident and emergency department of the Royal Aberdeen Children's Hospital from January to December 2001 as a result of a wrist, hand, or finger injury sustained from a blow by a ball were reviewed and the cause, type, and severity of the injury noted.

Altogether 187 children ( 125 boys, 69\%) were seen over the study period. Football (soccer) resulted in 120 (64\%) of the injuries, with 93 (78\%) sustained by boys. Serious injuries were noted in 69 cases -67 fractures and two dislocations (37\% of the total presentations). The fracture rate was higher in the injuries sustained outside school.

All injuries in this study were caused by a blow from a ball. Most football injuries in youngsters are mild, but their severity increases with age as children become heavier and achieve higher skill levels. The study concluded with the following recommendations. Firstly, using lighter balls for younger children would reduce the force of a blow. Secondly, weight categories would ensure that heavier players were not kicking or throwing balls at lighter players. Thirdly, awareness of the risk of hand and wrist injuries among parents and coaches should be increased.

Wider implementation of these modifications should be considered, and a register of injuries kept by sporting bodies would be of benefit in monitoring such injuries.

A British Journal of Sports Medicine 2003;37:351-353. 